\title{
Dysexecutive Performance of Elderly Patients with Chronic Hepatitis C Virus Infection
}

\author{
Tomader Taha Abdel Rahman*, Marwa Abdel Azeem Abdel Guaad, Ahmad Kamel Mortagy \\ Department of Geriatrics Medicine, Faculty of Medicine, Ain Shams University, Cairo, Egypt \\ Email: ${ }^{*}$ tomelhagyn@hotmail.com
}

Received 19 June 2014; revised 22 July 2014; accepted 20 August 2014

Copyright @ 2014 by authors and Scientific Research Publishing Inc.

This work is licensed under the Creative Commons Attribution International License (CC BY).

http://creativecommons.org/licenses/by/4.0/

(c) $\underset{\mathrm{EY}}{\mathrm{B}}$ Open Access

\section{Abstract}

Chronic infection with hepatitis C virus (HCV) is one of the most important causes of chronic liver disease, which can progress to cirrhosis and hepatocellular carcinoma (HCC). It is well established that advanced forms of the disease are accompanied by overt and global cognitive deficits (hepatic encephalopathy) but now there is a growing evidence that the alterations in cerebral function in patients with chronic HCV infection may appear long before the development of severe liver cirrhosis, it has been hypothesized that it is related to a direct effect of HCV on the brain; or the neurotoxic effect of HCV-related systemic inflammation. The purpose of the study was to assess the possible existence of executive dysfunction in chronic HCV infected patients. One hundred elderly patients aged 60 years and above agreed to participate in this study; 50 patients were HCV positive (cases) and 50 patients were HCV negative (controls). All participants were subjected to the following: diagnosis of HCV by detection of HCV antibodies using ELISA technique, non-invasive assessment of liver condition, and evaluation of executive functions using 5 neuropsychological tests. The study showed that there was a significant difference between cases and controls regarding 2 executive function tests related to the phonological loop component of working memory among HCV positive patients. The study concluded that chronic HCV infection is accompanied by dysexecutive performance.

\section{Keywords}

Elderly, Executive Functions, HCV

\section{Introduction}

Chronic infection with hepatitis C virus (HCV) is a growing global health issue affecting an estimated 170 mil-

*Corresponding author.

How to cite this paper: Rahman, T.T.A., Guaad, M.A.A.A. and Mortagy, A.K. (2014) Dysexecutive Performance of Elderly Patients with Chronic Hepatitis C Virus Infection. Advances in Aging Research, 3, 285-292.

http://dx.doi.org/10.4236/aar.2014.34037 
lion people [1]. Egypt has the highest prevalence of adult HCV infection in the world, affecting an average of 15\% $25 \%$ of the population in rural communities [2]. It is well established that advanced forms of the disease are accompanied by overt and global cognitive deficits (hepatic encephalopathy) [3]-[5]. Recently, researchers and clinicians have become increasingly aware of a group of HCV patients with mild liver disease that present with a less-overt pattern of neuropsychological impairment [6]-[11].

The cognitive process that organizes simple ideas, behaviors, and affects into complex actions, the one best action for the environmental cue, and the right step for the goal is called the executive function [12]. It includes the ability to initiate and stop actions, to monitor and change behavior as needed, and to plan future behavior when faced with novel tasks and situations [13]. Individuals with executive dysfunction have increased risk of functional decline and mortality [14]. So the purpose of this study was to investigate the possible existence of alterations in the executive functions in chronic HCV infected elderly patients.

\section{Subjects and Methods}

\subsection{Study Design}

Case control study.

\subsection{Participants}

One hundred elderly aged 60 years or more, 50 patients have chronic HCV infection (cases) and 50 healthy individuals not infected with HCV (controls).

\subsection{Study Settings}

The study was carried out in geriatrics medicine department, internal medicine department and outpatient clinics in Ain Shams University hospitals, Egypt, over the period from March 2012 to March 2013. The cases have chronic HCV infection and the controls were healthy elderly recruited from patients' relatives. This study was approved by the Ethical committee of Ain Shams University. All participants provided informed written consent before participating in this study.

\subsection{Methodology}

All participants were subjected to complete medical evaluation (including history, general examination and abdominal examination), non-invasive assessment of liver condition by assessment of liver enzymes, serum bilirubin (total and direct), serum albumin, international normalized ratio (INR), and abdominal ultrasound. Cases of cirrhosis were excluded if the patients have physical examination denoting cirrhosis, elevated liver enzymes, elevated serum bilirubin, serum albumin $(<3.5 \mathrm{~g} / \mathrm{dl})$, international normalized ratio (INR) (>1.0), or abdominal ultrasound showed liver cirrhosis.

Abdominal ultrasonography (US) is a specific, reliable, non-invasive, fast, and cost-effective test used for diagnosing cirrhosis [15] with specificity rate $82 \%$ [16].

Diagnosis of HCV infection was done by the use of enzyme-linked immunosorbent assay (ELISA). Three ml of blood was collected from each participant in a plain tube, it was allowed to clot and separated serum was used for the test. The detection of anti-HCV in serum was achieved by using a commercially available $3^{\text {rd }}$ generation ELISA kit (Axsym HCV 3.0, Abbott Laboratories, and Chicago, IL, USA) according to the manufacturer's instructions.

\subsection{Neuropsychological Assessment}

Before applying the executive function evaluation tests, all participants were subjected to comprehensive geriatric assessment including cognitive function assessment using mini-mental state examination (MMSE) [17]. This was done in order to exclude cases of dementia. Also, Geriatric depression scale 15 items (GDS-15) was performed to exclude cases of depression. Normal GDS score is $<5$ [18].

Assessment of executive functions was done using 5 neuropsychological tests [block design [19], clock drawing [20], digit span backward [19], animal verbal fluency [21], and the Executive Interview 25 (EXIT 25) [22].

Several neuropsychiatric tests are sensitive to executive function such as the Wisconsin Card Sorting Test [23], the stroop test [24] and The Tower of Hanoi test [25]. Unfortunately, these tests are difficult to administer and 
are seldom used as screening measures. However, other measures of executive function, such as the block design [19], clock drawing [20], digit span backward [19], animal verbal fluency [21], and the Executive Interview 25 (EXIT 25) [22] are more easily administered by clinicians [22] [26] [27].

Block design test requires participants to use blocks to make specific designs. The designs progress in difficulty from simple two-block designs to more complex, nine-block designs. The raw score ranges from 0 to 42 , this raw score is then converted into standard score. Normal standard score is $\geq 7$ [19].

In clock drawing test participants are asked to draw a circle and asked to draw numbers on it looks like a clock. They are then asked to draw the hands of the clock to read (10 past 11). Clock drawing is considered normal if the patient places the correct numbers, time, and the clock appears grossly normal [20].

Digit span backward requires participants to repeat a series of numbers, ranging in length from two to eight digits, in reverse sequence immediately after they are read aloud by the examiner. Normal score is $\geq 4$ [19].

Animal verbal fluency requires participants to enumerate as many animals (four legged) as possible within one minute. Score $\geq 12$ is considered normal [21].

EXIT 25 is 25 items bedside examination of executive function that takes 15 minutes. Each item is scored zero for a perfect answer, 2 for an incorrect answer, and 1 if the patient needs prompting to obtain a correct answer. The normal score is from 0 to 15 out of 50 points. Higher score suggests impairment [22].

Neuropsychological assessment was done blindly by trained physicians without knowing whether the participant is a case or a control.

\subsection{Exclusion Criteria}

The exclusion criteria included all factors affecting executive functions such as hypertension, diabetes mellitus, cerebrovascular diseases, mental retardation, dementia, depression, cardiovascular diseases, chronic kidney disease, other chronic liver diseases, severe fibrosis, liver cirrhosis, hepatitis B virus (HBV) infection, Former antiviral HCV treatment, human immunodeficiency virus (HIV) infection, and alcohol or drug abuse.

\subsection{Data Management and Statistical Analysis}

Data was collected and analytical statistics were done. $\chi^{2}$ test was used to test the association between categorical variables. Student's t-test was used to compare the two groups' means. Multivariate logistic regression analysis was done in this study. All proposed factors to be introduced for multivariate analysis, beside that they were all biologically plausible, were significant according to the findings obtained from data analysis. The level of significance was taken at $\mathrm{p}$ value $<0.05$. All statistical manipulation was carried out using the 15 th version of SPSS (SPSS, Chicago, IL, USA).

\section{Results}

In this study, 50 patients have HCV infection (cases) and 50 patients are healthy controls. The age of cases and controls ranged from 60 to 78 years and the mean age for cases and controls were $65.08 \pm 4.06$ and $65.60 \pm 4.95$ respectively. All participants were educated (Table 1 ).

Univariate analysis revealed significant association between chronic HCV infection and Digit span backward test and EXIT 25 (Table 2).

Multiple logistic regression analyses showed that, chronic HCV infection significantly is an independent risk factor of poor performance in digit span backward test $(\mathrm{p}=0.04, \mathrm{OR}=3.50)$, and EXIT 25 test $(\mathrm{p}=0.03, \mathrm{OR}=$ 15.32) (Table 3).

\section{Discussion}

The current study demonstrated the existence of impaired executive functions in patients with chronic HCV infection. We used strict criteria in selecting participants. The selected cases were HCV mono-infected with no evidence of overt cirrhosis. The controls were healthy elderly having normal liver with no viral hepatitis affection. As well as, the other risk factors affecting executive functions were excluded in this study.

Forton and his colleagues [6] in their preliminary study; 27 viremic patients with hepatitis due to HCV and 16 patients with cleared HCV; have demonstrated that cognitive dysfunction is apparent in patients with HCV with and without cirrhosis but they didn't concentrate on executive functions. It is now recognized that in elderly 
Table 1. Participants' characteristics.

\begin{tabular}{|c|c|c|c|}
\hline & Cases $(n=50)$ & Controls $(n=50)$ & $\mathrm{p}$ value \\
\hline Males [N (\%)] & $36(53.7 \%)$ & $31(46.3 \%)$ & 0.288 \\
\hline Age (mean \pm SD) & $65.08 \pm 4.06$ & $65.60 \pm 4.95$ & 0.567 \\
\hline Smokers [N (\%)] & $14(51.9 \%)$ & $13(48.1 \%)$ & 0.822 \\
\hline Education $\leq 12$ years $[\mathrm{N}(\%)]$ & 38 (50.7\%) & 37 (49.3\%) & 0.968 \\
\hline Below high school & $38(76.0 \%)$ & $38(76.0 \%)$ & \\
\hline High school & $3(6.0 \%)$ & $3(6.0 \%)$ & 1.000 \\
\hline Above high school & $9(18.0 \%)$ & $9(18.0 \%)$ & \\
\hline MMSE (mean \pm SD) & $28.22 \pm 1.11$ & $28.56 \pm 1.15$ & 0.135 \\
\hline GDS (mean \pm SD) & $1.46 \pm 0.89$ & $1.16 \pm 0.89$ & 0.094 \\
\hline Normal block design [N (\%)] & $23(50.00 \%)$ & $23(50.00 \%)$ & 1.000 \\
\hline Normal clock drawing test [N (\%)] & $13(37.1 \%)$ & $22(62.9 \%)$ & 0.059 \\
\hline Normal digit span backwards [N (\%)] & $8(30.8 \%)$ & $18(69.2 \%)$ & 0.000 \\
\hline Normal animal verbal fluency [N (\%)] & $12(48.0 \%)$ & $13(52.0 \%)$ & 0.817 \\
\hline Normal EXIT 25 [N (\%)] & $33(39.8 \%)$ & $50(60.2 \%)$ & 0.023 \\
\hline
\end{tabular}

N: Number, SD: Standard Deviation.

Table 2. Univariate analysis of factors affecting executive functions in the studied sample.

\begin{tabular}{cccccccccccc}
\hline & \multicolumn{2}{c}{ Block design } & \multicolumn{2}{c}{ Clock drawing test } & \multicolumn{2}{c}{ Digit span backward } & \multicolumn{2}{c}{ Animal verbal fluency test } & \multicolumn{2}{c}{ EXIT 25 } \\
& $\chi^{2}$ & $\mathrm{p}$ & $\chi^{2}$ & $\mathrm{p}$ & $\chi^{2}$ & $\mathrm{p}$ & $\chi^{2}$ & $\mathrm{p}$ & $\chi^{2}$ & $\mathrm{p}$ \\
Males & 0.25 & 0.62 & 0.04 & 0.84 & 0.08 & 0.78 & 1.22 & 0.27 & 1.83 & 0.18 \\
Smoking & 0.07 & 0.79 & 4.42 & 0.04 & 1.08 & 0.30 & 2.86 & 0.09 & 0.13 & 0.72 \\
Education $\leq 12$ years & 1.05 & 0.31 & 4.83 & 0.03 & 8.26 & 0.02 & 5.63 & 0.02 & 2.47 & 0.12 \\
HCV positive & 0.00 & 1.00 & 3.56 & 0.06 & 5.19 & 0.00 & 0.05 & 0.82 & 20.48 & 0.02 \\
& $\mathrm{t}$ & $\mathrm{p}$ & $\mathrm{t}$ & $\mathrm{p}$ & $\mathrm{t}$ & $\mathrm{p}$ & $\mathrm{t}$ & $\mathrm{p}$ & $\mathrm{t}$ & $\mathrm{p}$ \\
Age & 0.94 & 0.36 & 1.15 & 0.25 & 0.19 & 0.85 & 0.23 & 0.82 & 0.48 & 0.63 \\
MMSE & 0.12 & 0.90 & 1.86 & 0.07 & 0.76 & 0.45 & 0.87 & 0.39 & 0.52 & 0.61 \\
GDS & 0.85 & 0.40 & 1.32 & 0.19 & 0.37 & 0.71 & 1.52 & 0.13 & 1.41 & 0.16 \\
\hline
\end{tabular}

Table 3. Multiple logistic regression analysis of factors affecting executive functions in the studied sample.

\begin{tabular}{ccccc}
\hline & Digit span backward & EXIT 25 & p & OR (C.I.) \\
HCV +ve & $\mathrm{p}$ & OR (C.I.) & 0.03 & $15.32(1.36-172.66)$ \\
Education $\leq 12$ years & 0.04 & $3.50(1.08-11.39)$ & 0.11 & $6.59(0.63-68.09)$ \\
\hline
\end{tabular}

OR, Odds Ratio, C.I., Confidence Interval.

with normal cognitive function, there may be impairment in executive functions [13].

Previous researches have shown that HCV impairs power of concentration, attention, learning and mental flexibility [6] [9] [28]. This pattern of cognitive impairment can be attributed to dysfunction of subcortical brain systems [9] [28] [29]. In this study, HCV infected patients performed significantly worse than healthy controls in executive functions tests; digit span backward test $(\mathrm{p}=0.04, \mathrm{OR}=3.50)$, and EXIT 25 test $(\mathrm{p}=0.03$, OR $=$ 15.32). This executive dysfunction can be attributed to dysfunction of frontal, parietal, occipital, and temporal 
cortices suggesting diffuse brain pathology.

Digit span backward test; assesses number registration, encoding, storage, and retrieval capacity [19]; generated stronger activation in most areas, including the frontal (specially the right inferior frontal gyrus), the parietal, the occipital, and the temporal cortices [30].

EXIT25; assesses planning, initiation, and regulation of complex goal-directed behavior [22]; have been specifically associated with left frontal system structural lesions [31].

Historically, the executive functions have been seen as regulated by the prefrontal regions of the frontal lobes, but it is still a matter of ongoing debate if that really is the case [32]. Probably the frontal lobes participate in basically all of the executive functions, but it is not the only brain structure involved [32]-[34]. There is a direct evidence for functional connectivity between the prefrontal (PFC) and the rest of the brain like occipital and parietal cortices [35] when executive functions are used. As well as, there is a line of research which suggests that executive functions control is not only limited to a number of cortical (orbitofrontal, prefrontal) regions but also subcortical (basal ganglia) regions forming a specific neurocircuitry [36]-[38].

Hepatitis C is a member of the Flaviviridae, which is one of neurovirulent viruses. The etiology of cognitive dysfunction exhibited by patients with HCV is unknown. Previously, there was an increasing evidence suggests that there may be a direct effect of the virus on brain functioning via a "trojan horse" mechanism, similar to that hypothesized to occur in HIV-infected patients [6].

Recently, Fletcher and McKeating in vitro studies [39] suggest that HCV may disrupt BBB integrity. In chronically infected HCV patients, the virus produces approximately $10^{12}$ viral particles per day, which are released into the blood stream and encounter brain micro-vascular endothelial cells of the blood brain barrier (BBB). Direct viral infection of BBB endothelial cells may occur, resulting in apoptosis and BBB breakdown that could allow entry of inflammatory cytokines, viral particles and other neurotoxic substances that may affect the brain tissue and cause these neurological symptoms "executive dysfunction". This is also discussed in two studies, the first one [40] demonstrated HCV RNA in brain tissue consistent with mild neuropathologies observed in HCV infected patients. The second study; is a study of postmortem tissue; demonstrated that brain tissue from HCV infected subjects expressed significantly increased levels of proinflammatory cytokines IL-1, TNF- $\alpha$, IL-12, and IL-18 [41].

In the current study cognitive flexibility was assessed using animal verbal fluency test and it was found that there is no statistically significant difference between HCV positive patients and healthy controls. This result agreed with the results obtained by McAndrew et al. [11] who performed a study involved 37 HCV positive patients without liver cirrhosis, their cognitive flexibility was assessed using stroop interference test and the results were compared with 46 healthy controls. The results revealed intact cognitive flexibility among HCV positive patients.

In this study the visuospatial component of working memory was assessed by block design test [42] and clock drawing test [43], while the phonological loop component was assessed by the EXIT 25 test [22] and digit span backwards [44]. The results showed a significant difference between HCV positive patients and healthy controls in the scores of EXIT 25 and Digit span backward test indicating presence of impairment in the phonological loop component of working memory but there was no significant difference between HCV positive patients and healthy controls in the scores of block Design test and clock drawing test indicating that HCV positive patients have no impairment in the visuospatial component of working memory. This agreed with the study performed by Hilsabeck et al. [44]; the study involved 66 patients with chronic hepatitis $C$ with mean age 45.98 years, visuospatial and visuoconstructional abilities were assessed using Rey Complex Figure Test (modified version). The results of this study revealed that basic visuospatial and visuoconstructional abilities are relatively unaffected in patients with chronic hepatitis C who didn't develop cirrhosis.

In this study, there was no significant association between age and executive functions. This is because all participants' ages ranged from 60 to 78 years. This narrow range didn't allow us to detect the relation between age and executive functions which was reported in other researches [45] [46].

Consistent with previous findings [47]-[50], smoking history did not appear to have deleterious effects on elderly executive functions.

Recent studies [51] [52] have shown that educational status may influence cognitive test performance. This is in agreement with this study which revealed that less-educated people performed worse than more-educated people on executive functions tests; as clock drawing test, digit span backward and animal verbal fluency test. 


\section{Conclusion}

The study showed that chronic HCV infection was accompanied by dysexecutive performance even in the absence of overt liver cirrhosis suggesting direct action of the hepatitis $C$ virus on the brain.

\section{Study Limitations}

In this study exclusion of liver cirrhosis was determined by complete medical evaluation, laboratory assessment and abdominal ultrasound; these measures in spite of they are non invasive, fast, and cost-effective, they didn't give sure diagnosis of cirrhosis. The sure diagnosis of cirrhosis is by liver biopsy which couldn't be done as it is an invasive technique, or by the use of the non invasive measures such as fibro test or fibro scan which were not available in our hospital. As well as diagnosis of HCV infection was performed by the use of ELISA technique, it was better to be diagnosed by polymerase chain reaction (PCR).

\section{Disclosure Statement}

There is no conflict of interest.

\section{References}

[1] Lauer, G.M. and Walker, B.D. (2001) Hepatitis C Virus Infection. New England Journal of Medicine, 345, 41-52. http://dx.doi.org/10.1056/NEJM200107053450107

[2] Abdel-Wahab, M.F., Zakaria, S., Kamel, M., Abdel-Khaliq, M.K., Mabrouk, M.A., Salama, H., et al. (1994) High Seroprevalence of Hepatitis C Infection among Risk Groups in Egypt. The American Journal of Tropical Medicine and Hygiene, 51, 563-567.

[3] Binesh, N., Huda, A., Thomas, M.A., Wyckoff, N., Bugbee, M., Han, S., et al. (2006) Hepatic Encephalopathy: A Neurochemical Neuroanatomical, and Neuropsychological Study. Journal of Applied Clinical Medical Physics, 7, 86-96. http://dx.doi.org/10.1120/jacmp.2027.25374

[4] Pantiga, C., Rodrigo, L.R., Cuest, M., Lopez, L. and Arias, J.L. (2003) Cognitive Deficits in Patients with Hepatic Cirrhosis and in Liver Transplant Recipients. Journal of Neuropsychiatry and Clinical Neurosciences, 15, 84-89. http://dx.doi.org/10.1176/appi.neuropsych.15.1.84

[5] Mattarozzi, K., Campi, C., Guarino, M. and Stracciari, A. (2005) Distinguishing between Clinical and Minimal Hepatic Encephalopathy on the Basis of Specific Cognitive Impairment. Metabolic Brain Disease, 20, 243-249. http://dx.doi.org/10.1007/s11011-005-7212-1

[6] Forton, D.M., Thomas, H.C., Murphy, C.A., Allsop, J.M., Foster, G.R., Main, J., et al. (2002) Hepatitis C and Cognitive Impairment in a Cohort of Patients with Mild Liver Disease. Hepatology, 35, 433-439. http://dx.doi.org/10.1053/jhep.2002.30688

[7] Back-Madruga, C., Fontana, R. and Bielauskas, L. (2003) Predictors of Cognitive Impairment in Chronic Hepatitis C Patients Entering the HALT-C Trial. Journal of the International Neuropsychological Society, 9, 245-246.

[8] Collie, A. (2005) Cognition in Liver Disease. Liver International, 25, 1-8. http://dx.doi.org/10.1111/j.1478-3231.2005.01012.x

[9] Hilsabeck, R.C., Perry, W. and Hassanein, T.I. (2002) Neuropsychological Impairment in Patients with Chronic Hepatitis C. Hepatology, 35, 440-446. http://dx.doi.org/10.1053/jhep.2002.31257

[10] Karin, W., Martin, B., Jochen, K., Jochen, E. and Björn, A. (2005) Neurological and Neuropsychiatric Syndromes Associated with Liver Disease. AIDS, S3, 93-98.

[11] McAndrews, M.P., Farcnik, K., Carlen, P., Damyanovich, A., Mrkonjic, M., Jones, S., et al. (2005) Prevalence and Significance of Neurocognitive Dysfunction in Hepatitis C in the Absence of Correlated Risk Factors. Hepatology, 41, 801-808. http://dx.doi.org/10.1002/hep.20635

[12] American Psychiatric Association (1994) Diagnostic and Statistical Manual of Mental Disorders. 4th Edition, American Psychiatric Association, Washington DC, 135.

[13] Carey, C.L., Kramer, J.H., Josephson, S.A., Mungas, D., Reed, B.R., Schuff, N., et al. (2008) Subcortical Lacunes Are Associated with Executive Dysfunction in Cognitively Normal Elderly. Stroke, 39, 397-402. http://dx.doi.org/10.1161/STROKEAHA.107.491795

[14] Johnson, J.K., Lui, L.Y. and Yaffe, K. (2007) Executive Function, More Than Global Cognition, Predicts Functional Decline and Mortality in Elderly Women. The Journals of Gerontology Series A: Biological Sciences and Medical Sciences, 62, 1134-1141. 
[15] American College of Radiology, Expert Panel on Gastrointestinal Imaging (2002) Liver Lesion Characterization. American College of Radiology, Reston.

[16] Iacobellis, A., Fusilli, S., Mangia, A., Clemente, R., Festa, V., Giacobbe, A., et al. (2005) Ultrasonographic and Biochemical Parameters in the Non-Invasive Evaluation of Liver Fibrosis in Hepatitis C Virus Chronic Hepatitis. Alimentary Pharmacology Therapeutics, 22, 769-774.

[17] Folstein, M.F., Folstein, S.E. and McHugh, P.R. (1975) “Mini-Mental State”: A Practical Method for Grading the Cognitive State of Patients for the Clinician. Journal of Psychiatric Research, 12, 189-198. http://dx.doi.org/10.1016/0022-3956(75)90026-6

[18] Sheikh, J.A. and Yesavage, J.A. (1986) Recent Finding and Development of a Shorter Version. In: Brinn, T.L., Ed., Clinical Gerontology: A Guide to Assessment and Intervention, Hawarth Press, New York.

[19] Wechsler, D. (1997) Wechsler Adult Intelligence Scale. 3rd Edition, Harcourt Assessment, San Antonio.

[20] Borson, S., Brush, M., Gil, E., Scanlan, J., Vitaliano, P., Chen, J., et al. (1999) The Clock Drawing Test: Utility for Dementia Detection in Multiethnic Elders. Journals of Gerontology Series A: Biological Sciences and Medical Sciences, 54, 534-540. http://dx.doi.org/10.1093/gerona/54.11.M534

[21] Brucki, S.M. and Rocha, M.S. (2004) Category Fluency Test: Effects of Age, Gender and Education on Total Scores, Clustering and Switching in Brazilian Portuguese-Speaking Subjects. Brazilian Journal of Medical and Biological Research, 37, 1771-1777.

[22] Royall, D.R., Mahurin, R.K. and Gray, K. (1992) Bedside Assessment of Executive Cognitive Impairment: The Executive Interview (EXIT). Journal of the American Geriatrics Society, 40, 1221-1226.

[23] Heaton, R.K. (1981) A Manual for the Wisconsin Card Sorting Test. Psychological Assessment Services, Odessa, FL.

[24] Posner, M.I. and DiGirolamo, G.J. (1998) Executive Attention: Conflict, Target Detection and Cognitive Control. In: Parasuraman, R., Ed., The Attentive Brain, MIT Press, Cambridge.

[25] Welsh, M.C., Satterlee-Cartmell, T. and Stine, M. (1999) Towers of Hanoi and London: Contribution of Working Memory and Inhibition to Performance. Brain and Cognition, 41, 231-242. http://dx.doi.org/10.1006/brcg.1999.1123

[26] Lezak, M.D. (1995) Neuropsychological Assessment. 3rd Edition, Oxford University Press, Oxford.

[27] Schillerstrom, J.E., Rickenbacker, D., Joshi, K.G., et al. (2009) Executive Function in Self-Neglecting Adult Protective Services Referrals Compared with Elder Psychiatric Outpatients. American Journal of Geriatric Psychiatry, 17, 907910. http://dx.doi.org/10.1097/JGP.0b013e3181b4bf64

[28] Forton, D.M., Allsop, J.M., Cox, I.J., Hamilton, G., Wesnes, K., Thomas, H.C., et al. (2005) A Review of Cognitive Impairment and Cerebral Metabolite Abnormalities in Patients with Hepatitis C Infection. AIDS, 19, 53-63. http://dx.doi.org/10.1097/01.aids.0000192071.72948.77

[29] Forton, D.M., Thomas, H.C. and Taylor-Robinson, S.D. (2004) Central Nervous System Involvement in Hepatitis C Virus Infection. Metabolic Brain Disease, 19, 383-391. http://dx.doi.org/10.1023/B:MEBR.0000043983.42843.ac

[30] Sun, X.W., Zhang, X.C., Chen, X.C., Zhang, P., Bao, M., Zhang, D.R., et al. (2005) Age-Dependent Brain Activation during Forward and Backward Digit Recall Revealed by fMRI. Neuroimage, 26, 36-47. http://dx.doi.org/10.1016/j.neuroimage.2005.01.022

[31] Stokholm, J., Vogel, A., Gade, A. and Waldemar, G. (2005) The Executive Interview as a Screening Test for Executive Dysfunction in Patients with Mild Dementia. Journal of the American Geriatrics Society, 53, 1577-1581. http://dx.doi.org/10.1111/j.1532-5415.2005.53470.x

[32] Alvarez, J. and Emory, E. (2006) Executive Function and the Frontal Lobes: A Meta-Analytic Review. Neuropsychology Review, 16, 17-42. http://dx.doi.org/10.1007/s11065-006-9002-x

[33] Lezak, M.D., Howieson, D.B. and Loring, D.W. (2004) Neuropsychological Assessment. 4th Edition, Oxford University Press, New York.

[34] Clark, L., Bechara, A., Damasio, H., Aitken, M.R.F., Sahakian, B.J., Robbins, T.W.L., et al. (2008) Differential Effects of Insular and Ventromedial Prefrontal Cortex Lesions on Risky Decision Making. Brain, 131, 1311-1322. http://dx.doi.org/10.1007/s11065-006-9002-x

[35] Shokri-Kojori, E., Motes, M.A., Rypma, B. and Krawczyk, D.C. (2012) The Network Architecture of Cortical Processing in Visuo-Spatial Reasoning. Scientific Reports, 2, Article No. 411.

[36] Leh, S.E., Petrides, M. and Strafella, A.P. (2010) The Neural Circuitry of Executive Functions in Healthy Subjects and Parkinson's Disease. Neuropsychopharmacology, 35, 70-85. http://dx.doi.org/10.1038/npp.2009.88

[37] Dirnberger, G., Frith, C.D. and Jahanshahi, M. (2005) Executive Dysfunction in Parkinson’s Disease Is Associated with Altered Pallidal-Frontal Processing. Neuroimage, 25, 588-599. http://dx.doi.org/10.1016/j.neuroimage.2004.11.023

[38] Zgaljardic, D.J., Borod, J.C., Foldi, N.S., Mattis, P.J., Gordon, M.F., Feigin, A., et al. (2006) An Examination of Ex- 
ecutive Dysfunction Associated with Frontostriatal Circuitry in Parkinson’s Disease. Journal of Clinical and Experimental Neuropsychology, 28, 1127-1144. http://dx.doi.org/10.1080/13803390500246910

[39] Fletcher, N.F. and McKeating, J.A. (2012) Hepatitis C Virus and the Brain. Journal of Viral Hepatitis, 19, $301-306$. http://dx.doi.org/10.1111/j.1365-2893.2012.01591.x

[40] Fishman, S.L., Murray, J.M., Eng, F.J., Walewski, J.L., Morgello, S. and Branch, A.D. (2008) Molecular and Bioinformatic Evidence of Hepatitis C Virus Evolution in Brain. The Journal of Infectious Diseases, 197, 597-607. http://dx.doi.org/10.1086/526519

[41] Wilkinson, J., Radkowski, M., Eschbacher, J.M. and Laskus, T. (2010) Activation of Brain Macrophages/Microglia Cells in Hepatitis C Infection. Gut, 59, 1394-1400. http://dx.doi.org/10.1086/526519

[42] Groth-Marnat, G. and Teal, M. (2000) Block Design as a Measure of Everyday Spatial Ability: A Study of Ecological Validity. Perceptual and Motor Skills, 90, 522-526. http://dx.doi.org/10.2466/pms.2000.90.2.522

[43] Royall, D.R., Cordes, J.A. and Polk, M. (1998) CLOX: An Executive Clock Drawing Task. Journal of Neurology, Neurosurgery Psychiatry, 64, 588-594. http://dx.doi.org/10.1136/jnnp.64.5.588

[44] Hilsabeck, R.C., Hassanein, T.I., Carlson, M.D., et al. (2003) Cognitive Functioning and Psychiatric Symptomatology in Patients with Chronic Hepatitis C. Journal of the International Neuropsychological Society, 9, 847-854. http://dx.doi.org/10.1136/jnnp.64.5.588

[45] Prakash, R.S., Erickson, K.I., Colcombe, S.J., Kim, J.S., Voss, M.W. and Kramer, A.F. (2009) Age-Related Differences in the Involvement of the Prefrontal Cortex in Attentional Control. Brain and Cognition, 71, 328-335. http://dx.doi.org/10.1016/j.bandc.2009.07.005

[46] Iavarone, A., Lorè, E., De Falco, C., Milan, G., Mosca, R., Pappatà, S., et al. (2011) Dysexecutive Performance of Healthy Oldest Old Subjects on the Frontal Assessment Battery. Aging Clinical and Experimental Research, 23, 351356.

[47] Schinka, J.A., Vanderploeg, R.D., Rogish, M., Graves, A.B., Mortimer, J.A. and Ordoric, P.I. (2002) Effects of the Use of Alcohol and Cigarettes on Cognition in Elderly Adults. Journal of the International Neuropsychological Society, 8, 811-818. http://dx.doi.org/10.1017/S135561770286009X

[48] Chen, W.T., Wang, P.N., Wang, S.J., Fuh, J.L., Lin, K.N. and Liu, H.C. (2003) Smoking and Cognitive Performance in the Community Elderly: A Longitudinal Study. Journal of Geriatric Psychiatry and Neurology, 16, 18-22. http://dx.doi.org/10.1177/0891988702250510

[49] Razani, J., Boone, K., Lesser, I. and Weiss, D. (2004) Effects of Cigarette Smoking History on Cognitive Functioning in Healthy Older Adults. The American Journal of Geriatric Psychiatry, 12, 404-411.

[50] Reitz, C., Luchsinger, J., Tang, M.X. and Mayeux, R. (2005) Effect of Smoking and Time on Cognitive Function in the Elderly without Dementia. Neurology, 65, 870-875. http://dx.doi.org/10.1212/01.wnl.0000176057.22827.b7

[51] Farias, S.T., Mungas, D., Hinton, L. and Haan, M. (2011) Demographic, Neuropsychological and Functional Predictors of Rate of Longitudinal Cognitive Decline in Hispanic Older Adults. The American Journal of Geriatric Psychiatry, 19, 440-450.

[52] Souza Cde, O., Voos, M.C., Francato, D.V., Chien, H.F. and Barbosa, E.R. (2013) Influence of Educational Status on Executive Function and Functional Balance in Individuals with Parkinson Disease. Cognitive and Behavioral Neurology, 26, 6-13. 
Scientific Research Publishing (SCIRP) is one of the largest Open Access journal publishers. It is currently publishing more than 200 open access, online, peer-reviewed journals covering a wide range of academic disciplines. SCIRP serves the worldwide academic communities and contributes to the progress and application of science with its publication.

Other selected journals from SCIRP are listed as below. Submit your manuscript to us via either submit@scirp.org or Online Submission Portal.
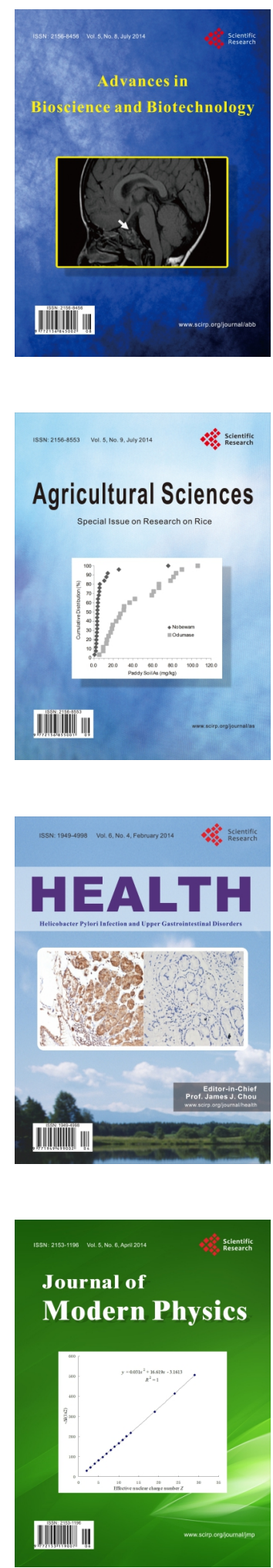
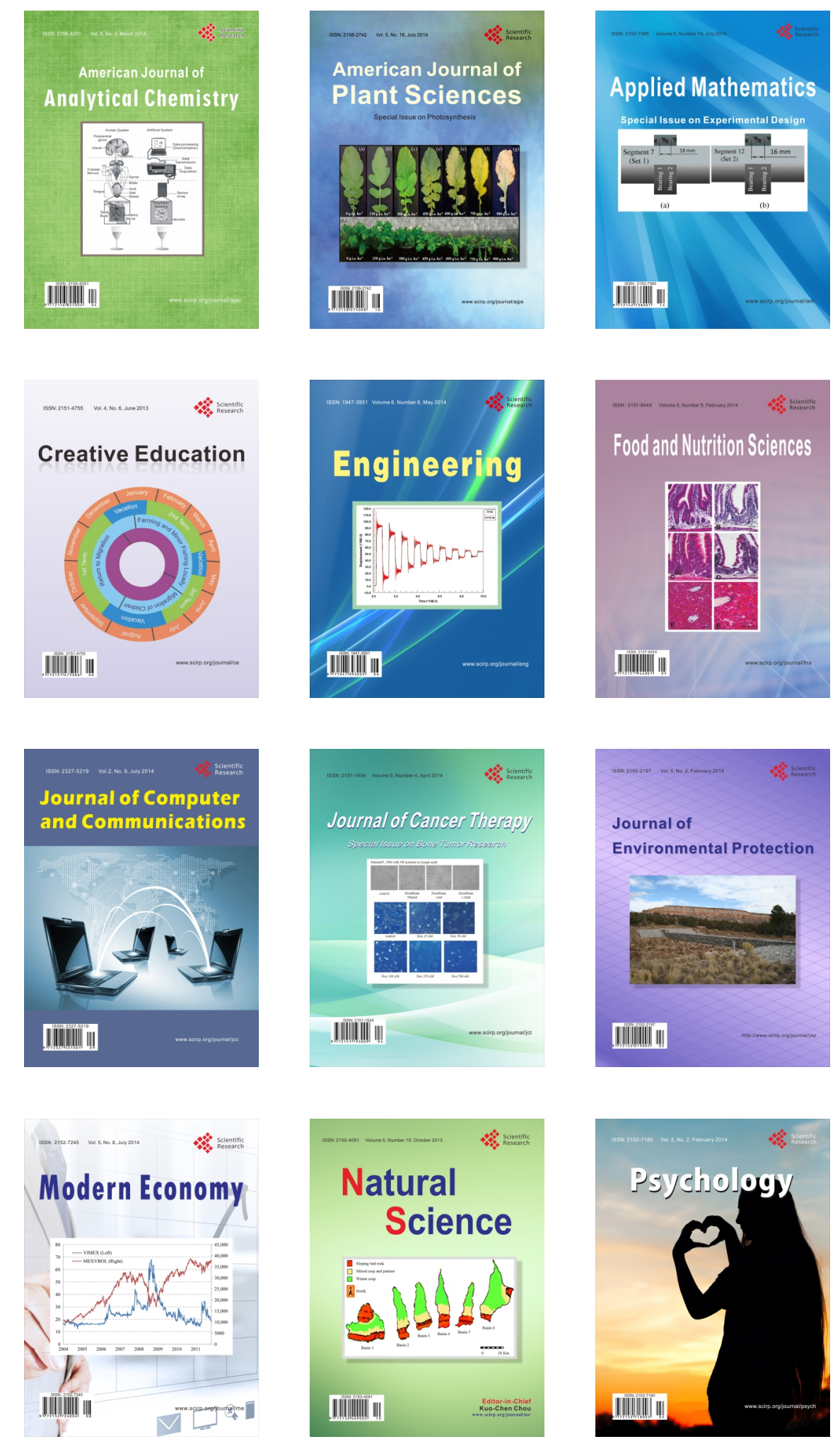